\title{
Chytridiales (Chytridiomycota) do Parque Estadual da Serra da Cantareira, SP, Brasil ${ }^{1}$
}

\author{
Cristiane de Almeida Nascimento ${ }^{2,3}$ e Carmen Lidia Amorim Pires-Zottarelli ${ }^{2}$
}

Recebido em 10/12/2007. Aceito em 17/09/2008

\begin{abstract}
RESUMO - (Chytridiales (Chytridiomycota) do Parque Estadual da Serra da Cantareira, SP, Brasil). Para o estudo da diversidade de Chytridiales, coletas mensais de água e solo foram realizadas, de junho/2005 a junho/2006, no Parque Estadual da Serra da Cantareira, Estado de São Paulo. O isolamento destes fungos foi realizado por meio do método de iscagem múltipla de amostras de água e solo, em laboratório, com substratos celulósicos, quitinosos e queratinosos. Dezenove espécies foram identificadas, sendo quatro novas ocorrências para o Brasil, Cladochytrium setigerum Karling, Diplophlyctis intestina (Schenk) J. Schröt, Rhizophydium macroporosum Karling e Solutoparies pythii Whiffen ex W.H. Blackw. \& Powell, e Septochytrium willoughbyi Dogma primeira citação para o Estado de São Paulo.
\end{abstract}

Palavras-chave: diversidade, Fungi, Mata Atlântica, quitridiomicetos

ABSTRACT - (Chytridiales (Chytridiomycota) from Serra da Cantareira State Park, São Paulo State, Brazil). A study of Chytridiales diversity was based on water and soil samples collected monthly from June/2005 to June/2006 in the Serra da Cantareira State Park, São Paulo State. The isolation of these fungi was carried out in the laboratory treating the water and soil samples by the multiple baiting technique with cellulosic, chitinous and keratinous substrates. Nineteen species were identified with four new citations for Brazil, Cladochytrium setigerum Karling, Diplophlyctis intestina (Schenk) J. Schröt, Rhizophydium macroporosum Karling and Solutoparies pythii Whiffen ex W.H. Blackw. \& Powell. Septochytrium willoughbyi Dogma is recorded for the first time in São Paulo State.

Key words: Atlantic Rainforest, chytrids, diversity, Fungi

\section{Introdução}

Chytridiales inclui organismos cosmopolitas que podem ser encontrados em ambientes aquáticos, continentais ou marinhos, e terrestres, vivendo saprobiamente ou parasitando algas, animais microscópicos, outros fungos, anfíbios e, mais raramente, plantas superiores de importância econômica (Alexopoulos et al. 1996). A ordem está inserida no Reino Fungi, Filo Chytridiomycota, sendo representada por quatro famílias, 80 gêneros e 600 espécies (Kirk et al. 2001).

Estes fungos apresentam talo cenocítico, de desenvolvimento endógeno ou exógeno, holocárpico ou eucárpico, monocêntrico ou policêntrico. A reprodução assexuada ocorre por meio de zoósporos posteriormente uniflagelados e, a sexuada, desconhecida em grande parte das espécies, por copulação planogamética, copulação de gametângios ou somatogamia (Alexopoulos et al. 1996; Kirk et al. 2001).

Em áreas de Mata Atlântica no Brasil, poucos foram os estudos taxonômicos realizados com Chytridiales (Rogers et al. 1970; Schoenlein-Crusius et al. 1990; 1992; Schoenlein-Crusius \& Milanez 1989; 1998; PiresZottarelli et al. 1996; Pires-Zottarelli \& Rocha 2007; dentre outros), e se considerando a grande importância deste bioma, existe a necessidade de outros trabalhos que contribuam para a ampliação do conhecimento da diversidade destes organismos no país.

O objetivo deste estudo foi realizar o levantamento das espécies de Chytridiales presentes no Parque Estadual da Serra da Cantareira, uma vez que referências destes fungos inexistiam para o local.

\footnotetext{
Parte da Dissertação de Mestrado da primeira Autora

Instituto de Botânica de São Paulo, Seção de Micologia e Liquenologia, C. Postal 3005, 01061-970 São Paulo, SP, Brasil

Autor para correspondência: crisbotanic@yahoo.com.br
} 


\section{Material e métodos}

O Parque Estadual da Serra da Cantareira, localizado no Estado de São Paulo (2332'36”'S e 46037'59”W), possui área de aproximadamente 7.916 ha, abrangendo parte dos municípios de Caieiras, Mairiporã, Guarulhos e extremo norte de São Paulo, sendo considerado a maior unidade de conservação do mundo situada em perímetro urbano. Em função de sua grande importância, em 1994 foi declarado pela UNESCO como parte da Reserva da Biosfera do Cinturão Verde de São Paulo. O Parque compreende quatro núcleos, Pedra Grande, Engordador, Águas Claras e Cabuçu, todos destinados a fins científicos, culturais, educativos e recreativos. O núcleo Engordador, local escolhido para a realização deste estudo, possui trilhas que permitem contato mais próximo com a flora característica da Mata Atlântica, garantindo também o acesso ao rio Engordador e vários outros corpos d'água como, córregos e cachoeiras (Secretaria do Meio Ambiente 2003).

Para o levantamento de Chytridiales, sete pontos foram selecionados para as coletas de água e solo, as quais foram realizadas mensalmente, de junho/2005 a junho/2006, totalizando 13 coletas que permitiram a obtenção de 182 amostras (91 de água e 91 de solo). As amostras coletadas foram iscadas e tratadas conforme metodologia tradicional utilizada para o estudo de fungos zoospóricos, descrita em Milanez (1989). O processo de iscagem múltipla das amostras de água e solo foi conduzido em laboratório, consistindo na utilização de substratos celulósicos (semente de sorgo, epiderme de cebola, palha de milho, grãos de pólen, celofane), quitinoso (exoesqueleto de camarão) e queratinosos (ecdise de cobra, cabelo loiro de crianças).

Os isolados foram identificados com auxílio de literatura específica constituída, principalmente Sparrow (1960) e Karling (1977), além de artigos contendo descrições originais dos táxons. Os espécimes foram incorporados ao Herbário Científico "Maria Eneyda P. Kauffmann Fidalgo" do Instituto de Botânica, São Paulo (SP) em lâminas semi-permanentes montadas com lactofenol e azul de algodão, resina polivinílica com glicerina e/ou resina polivinílica com glicerina, lactofenol e azul de algodão.

\section{Resultados e discussão}

Dezenove espécies de Chytridiales, representando os gêneros Chytriomyces, Cladochytrium, Diplophlyctis, Entophlyctis, Nowakowskiella, Phlyctochytrium, Rhizophydium, Septochytrium, Septosperm e Solutoparies, com 327 isolados, foram identificadas, as quais são descritas, comentadas e ilustradas, sendo quatro novas citações para o Brasil e uma nova ocorrência para o Estado de São Paulo (Tab. 1).

\section{FILO CHYTRIDIOMYCOTA}

\section{CHYTRIDIALES}

\section{CHYTRIDIACEAE}

Chave para as espécies de Chytriomyces

1. Zoosporângios com apêndice C. appendiculatus

1. Zoosporângios sem apêndice

2. Zoosporângios ornamentados C. spinosus

2. Zoosporângios lisos

3. Zoósporos com uma gotícula lipídica hialina .................................. hyalinus

3. Zoósporos com uma gotícula lipídica dourada C. aureus

Chytriomyces appendiculatus Karling, Bull. Torrey Bot. Club 74: 335. 1947.

Fig. 1-2

Talo eucárpico, monocêntrico, extra-intramatrical. Zoosporângios hialinos em isolados jovens, normalmente tornando-se marrons nos isolados mais antigos, operculados, irregularmente piriformes, 30-67,5×12,5-45 $\mu \mathrm{m}$, ovais, 17,5-42,5×13-27,5 $\mu \mathrm{m}$, raramente esféricos; parede lisa; com apêndice; sem apófise. Sistema rizoidal ramificado, extensivo, um eixo principal saindo da base do zoosporângio. Zoósporos com uma gotícula lipídica hialina, liberados por meio da abertura do opérculo formado na parede do zoosporângio e envolvidos por uma matriz gelatinosa hialina, onde permanecem agrupados antes de sua dispersão. Esporos de resistência âmbar, predominantemente irregulares, 17-25x

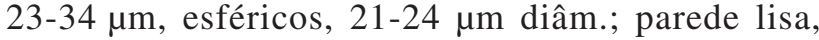
espessada; geralmente com apêndice; conteúdo granular com um vacúolo central; germinação não observada.

Material examinado: BRASIL. São Paulo: São Paulo, Parque Estadual da Serra da Cantareira, amostras de água, 8/VI/2005, 6/VII/2005, 11/VIII/2005, 21/IX/2005, 19/X/2005, 17/XI/2005, 7/XII/2005, 26/I/2006, 22/II/2006, 27/IV/2006, 19/V/2006, 5/VI/2006, e de solo, 11/VIII/2005, 21/IX/2005, 26/I/2006, 22/II/2006, 31/III/2006, 27/IV/2006, 19/V/2006, 5/VI/2006, em exoesqueleto de camarão, C.A. Nascimento 381611 (SP).

Distribuição no Brasil: Minas Gerais: Ingaí (J.M. Oliveira, dados não publicados); São Paulo: São Paulo (Pires-Zottarelli \& Rocha 2007).

Os isolados examinados apresentaram zoosporângios irregularmente piriformes pouco menores que os descritos por Karling (1947), de 30-90×10-50 $\mu \mathrm{m}$, e Pires-Zottarelli \& Rocha (2007), de 62-100×45-87 $\mu \mathrm{m}$, concordando com as demais características citadas pelos 
Tabela 1. Espécies de Chytridiales isolados do Parque Estadual da Serra da Cantareira, SP, Brasil, de junho/2005 a junho/2006. (A =Água/ $\mathrm{S}=$ Solo)

\begin{tabular}{|c|c|c|c|c|c|c|c|c|c|c|c|c|c|c|}
\hline \multirow[b]{2}{*}{ Táxons/Meses } & \multicolumn{7}{|c|}{2005} & \multicolumn{7}{|c|}{2006} \\
\hline & jun. & jul. & ago. & set. & out. & nov. & dez. & jan. & fev. & mar. & abr. & mai. & jun. & $\mathrm{f}(\%)$ \\
\hline \multicolumn{15}{|l|}{ REINO FUNGI } \\
\hline \multicolumn{15}{|l|}{ FILO CHYTRIDIOMYCOTA } \\
\hline \multicolumn{15}{|l|}{ CHYTRIDIALES } \\
\hline \multicolumn{15}{|l|}{ CHYTRIDIACEAE } \\
\hline $\begin{array}{l}\text { Chytriomyces apendiculatus } \\
\text { Karling }\end{array}$ & $\mathrm{A} / \mathrm{S}$ & $\mathrm{A} / \mathrm{S}$ & $\mathrm{A} / \mathrm{S}$ & $\mathrm{A} / \mathrm{S}$ & A & A & $\mathrm{A} / \mathrm{S}$ & $\mathrm{A} / \mathrm{S}$ & $\mathrm{A} / \mathrm{S}$ & A & S & $\mathrm{A} / \mathrm{S}$ & $\mathrm{A} / \mathrm{S}$ & 100 \\
\hline C. hyalinus Karling & $\mathrm{A} / \mathrm{S}$ & - & A & A & A & - & A & A & A & A & A & A & $\mathrm{A} / \mathrm{S}$ & 84,6 \\
\hline C. aureus Karling & $\mathrm{A} / \mathrm{S}$ & A & A & A & A & A & A & A & A & A & A & A & A & 100 \\
\hline C. spinosus Fay & A & - & - & - & - & - & - & - & - & - & - & - & - & 7,7 \\
\hline Phyctochytrium aureliae Ajello & - & - & - & - & - & - & - & - & - & S & - & - & - & 7,7 \\
\hline Rhizophydium elyensis Sparrow & - & - & S & - & S & - & - & S & S & S & - & S & S & 53,8 \\
\hline R. macroporosum Karling** & - & - & S & - & - & - & $\mathrm{S}$ & - & S & - & - & - & - & 23,1 \\
\hline R. stipitatum Sparrow & $\mathrm{S}$ & - & - & $\mathrm{S}$ & S & - & A & S & - & - & - & - & - & 38,5 \\
\hline Septosperma rizophydii & $\mathrm{S}$ & $S$ & S & $\mathrm{S}$ & S & - & - & - & - & - & - & S & - & 46,1 \\
\hline Whiffen ex W.H. Blackwell \& M.J. Powel & & & & & & & & & & & & & & \\
\hline $\begin{array}{l}\text { Solutoparies pythii Whiffen ex } \\
\text { W.H. Blackwell \& M.J. Powell** }\end{array}$ & - & - & - & - & - & - & - & A & - & - & - & - & - & 7,7 \\
\hline \multicolumn{15}{|l|}{ CLADOCHYTRIACEAE } \\
\hline Cladochytrium replicatum Karling & $\mathrm{A} / \mathrm{S}$ & $\mathrm{A} / \mathrm{S}$ & $\mathrm{A} / \mathrm{S}$ & $\mathrm{A} / \mathrm{S}$ & $S$ & $\mathrm{~A} / \mathrm{S}$ & $\mathrm{A} / \mathrm{S}$ & A & $\mathrm{A} / \mathrm{S}$ & A & - & A & A & 92,3 \\
\hline C. setigerum Karling** & - & - & $\mathrm{S}$ & - & - & $\mathrm{S}$ & A & - & $\mathrm{S}$ & A & - & - & - & 38,5 \\
\hline C. tenue Nowakowski & $\mathrm{A} / \mathrm{S}$ & A & $\mathrm{S}$ & A & - & S & - & S & $\mathrm{S}$ & $\mathrm{S}$ & - & - & - & 61,5 \\
\hline $\begin{array}{l}\text { Nowakowskiella elegans (Nowak.) } \\
\text { Schroeter }\end{array}$ & $\mathrm{A} / \mathrm{S}$ & - & $\mathrm{A} / \mathrm{S}$ & $\mathrm{A} / \mathrm{S}$ & S & A & - & - & A & $S$ & - & - & $S$ & 61,5 \\
\hline N. multispora Karling & - & - & - & - & $\mathrm{A} / \mathrm{S}$ & A & - & - & - & - & $S$ & A & A & 38,5 \\
\hline Septochytrium willoughbyi Dogma* & A & $\mathrm{A} / \mathrm{S}$ & $\mathrm{S}$ & $\mathrm{A} / \mathrm{S}$ & $\mathrm{S}$ & $\mathrm{A} / \mathrm{S}$ & S & $\mathrm{A} / \mathrm{S}$ & $\mathrm{A} / \mathrm{S}$ & $S$ & S & $\mathrm{S}$ & - & 92,3 \\
\hline \multicolumn{15}{|l|}{ ENDOCHYTRIACEAE } \\
\hline $\begin{array}{l}\text { Diplophlyctis sarcoptoides (H.E. Petersen) } \\
\text { Dogma** }\end{array}$ & A & - & A & $\mathrm{S}$ & - & $S$ & - & - & A & - & $\mathrm{A} / \mathrm{S}$ & $\mathrm{S}$ & A & 61,5 \\
\hline D. intestina (Shenk) J. Schroeter* & A & - & $\mathrm{S}$ & - & S & - & - & - & - & $\mathrm{A} / \mathrm{S}$ & - & - & - & 30,8 \\
\hline Entophlyctis luteolus Longcore & A & $\mathrm{A} / \mathrm{S}$ & $\mathrm{S}$ & $\mathrm{A} / \mathrm{S}$ & - & $\mathrm{S}$ & $\mathrm{A} / \mathrm{S}$ & S & $S$ & $\mathrm{~S}$ & - & $\mathrm{S}$ & - & 76,9 \\
\hline Total & 33 & 24 & 30 & 31 & 21 & 25 & 26 & 24 & 31 & 21 & 11 & 24 & 26 & 327 \\
\hline
\end{tabular}

*Primeira citação para o Estado de São Paulo; **Primeira citação para o Brasil.

autores. A primeira citação de $C$. appendiculatus para o Brasil é referente ao material isolado de amostras de água e solo coletadas em áreas de cerrado no Estado de São Paulo (Pires-Zottarelli \& Rocha 2007).

Chytriomyces aureus Karling, Am. J. Bot. 32: 363. 1945.

Fig. 3

Talo eucárpico, monocêntrico, extra-intramatrical. Zoosporângios hialinos, operculados, esféricos, 16-45 $\mu \mathrm{m}$ diâm.; parede lisa; sem apêndice; apófise, quando presente, esférica a subesférica. Sistema rizoidal ramificado, extensivo, um eixo principal saindo da base do zoosporângio ou de uma apófise. Zoósporos com uma gotícula lipídica dourada, liberados por meio de opérculo formado na parede do zoosporângio e envolvidos por uma matriz gelatinosa hialina contínua com o zoosporângio, onde permanecem agrupados antes de sua dispersão. Esporos de resistência não observados.

Material examinado: BRASIL. São Paulo: São
Paulo, Parque Estadual da Serra da Cantareira, amostras de água, 8/VI/2005, 6/VII/2005, 11/VIII/2005, 21/IX/2005, 19/X/2005, 17/XI/2005, 7/XII/2005, 26/I/2006, 22/II/2006, 31/III/2006, 27/IV/2006, 19/V/2005, 5/VI/2006, e de solo, 8/VI/2005, em exoesqueleto de camarão, C.A. Nascimento 381612 (SP).

Distribuição no Brasil: Amazonas: Flores Nabuco (Karling 1945a); Piauí: Parque Nacional de Parque Nacional de Sete Cidades (Rocha 2006); São Paulo: São Paulo (Pires-Zottarelli \& Rocha 2007).

Os zoosporângios esféricos dos espécimes examinados se apresentaram pouco maiores que os descritos por Karling (1945a) que menciona de 8-40 $\mu \mathrm{m}$ diâm., e menores que Pires-Zottarelli \& Rocha (2007), de 32-68 um diâm. Os isolados demonstraram crescimento apenas em substrato quitinoso, exoesqueleto de camarão, como relatado por Karling (1945a) e PiresZottarelli \& Rocha (2007). Originalmente a espécie foi isolada de substrato quitinoso em Flores Nabuco, AM, 
Brasil (Karling, 1945a), porém Sparrow (1960) também a relata em substrato celulósico, epiderme de cebola.

Chytriomyces hyalinus Karling, Am. J. Bot. 32: 363. 1945.

Fig. 4

Talo eucárpico, monocêntrico, extra-intramatrical. Zoosporângios hialinos, operculados, esféricos, 17-26 $\mu \mathrm{m}$ diâm.; parede lisa; sem apêndice; apófise, quando presente, esférica a subesférica. Sistema rizoidal ramificado, extensivo, um eixo principal saindo da base do zoosporângio ou de uma apófise. Zoósporos com uma gotícula lipídica hialina, liberados por meio de opérculo formado na parede do zoosporângio e envolvidos por uma matriz gelatinosa hialina, onde permanecem agrupados antes de sua dispersão. Esporos de resistência não observados.

Material examinado: BRASIL. São Paulo: São Paulo, Parque Estadual da Serra da Cantareira, amostras de água, 8/VI/2005, 11/VIII/2005, 21/IX/2005, 19/X/2005, 17/XII/2005, 26/I/2006, 22/II/2006, 31/III/2006, 27/IV/2006, 5/VI/2006, e de solo, 8/VI/2006, em exoesqueleto de camarão, C.A. Nascimento 381613 (SP).

Distribuição no Brasil: Amazonas: Manaus (Karling 1945b); Minas Gerais: Ingaí (J.M. Oliveira, dados não publicados); Piauí: Parque Nacional de Parque Nacional de Sete Cidades (Rocha 2006); São Paulo: Cananéia (Booth 1979) e São Paulo (Rocha \& Pires-Zottarelli 2002; Pires-Zottarelli \& Rocha 2007).

Os espécimes examinados apresentaram zoosporângios esféricos menores que os descritos por Karling (1945a), que cita de 10-60 um diâm., e PiresZottarelli \& Rocha (2007), de 30-67 $\mu$ m diâm. Os espécimes foram isolados apenas em substrato quitinoso, exoesqueleto de camarão, como referido por Karling (1945a) e Pires-Zottarelli \& Rocha (2007); porém, Sparrow (1960) também menciona sua ocorrência em substrato celulósico, epiderme de cebola.

Chytriomyces spinosus Fay, Mycologia 39: 152-157. 1947.

Fig. 5

Talo eucárpico, monocêntrico, extra-intramatical. Zoosporângios hialinos, operculados, obpiriformes, 15-42,5 ×10-32,5 $\mu \mathrm{m}$; parede com ornamentações em forma de delicados espinhos agudos, não bifurcados; sem apêndice; sem apófise. Sistema rizoidal ramificado, extensivo, um eixo principal saindo da base do zoosporângio. Zoósporos com uma gotícula lipídica hialina, liberados por meio de opérculo formado na parede do zoosporângio e envolvidos por uma matriz gelatinosa hialina, onde permanecem agrupados antes de sua dispersão. Esporos de resistência não observados.
Material examinado: BRASIL. São Paulo: São Paulo, Parque Estadual da Serra da Cantareira, amostras de água, 8-VI-2005, em epiderme de cebola, C.A. Nascimento 381614 (SP).

Distribuição no Brasil: Amazonas: Manaus (M.I.L. Silva, dados não publicados); Piauí: Parque Nacional de Sete Cidades (Rocha 2006); São Paulo: São Paulo (Pires-Zottarelli \& Rocha 2007).

Os isolados apresentaram crescimento apenas em substrato celulósico, epiderme de cebola, concordando com Fay (1947) e Pires-Zottarelli \& Rocha (2007). A espécie foi isolada pela primeira vez no Brasil por M.I.L. Silva (dados não publicados), em amostras de água e solo coletadas em Manaus, Estado do Amazonas.

Phlyctochytrium aureliae Ajello, Mycologia 37: 110. 1945.

Fig. 6

Talo eucárpico, monocêntrico, extra-intramatrical. Zoosporângios hialinos, inoperculados, esféricos, 20-50 $\mu \mathrm{m}$ diâm.; parede com numerosas ornamentações em forma de espinhos bifurcados, distribuídos de forma desorganizada; com apófise composta. Sistema rizoidal ramificado, extensivo. Zoósporos com uma gotícula lipídica; liberação não observada. Esporos de resistência não observados.

Material examinado: BRASIL. São Paulo: São Paulo, Parque Estadual da Serra da Cantareira, amostra de solo, 19/V/2006, em ecdise de cobra, C.A. Nascimento 393251 (SP).

Distribuição no Brasil: São Paulo: Limeira, São Bernardo do Campo, Pedrinhas, Riacho Grande (A.I. Milanez, dados não publicados).

Os zoosporângios observados apresentaram-se maiores que os mencionados por Ajello (1945), que cita de 12-35 $\mu$ m diâm. A espécie foi isolada de substrato queratinoso (ecdise de cobra), porém, Ajello (1945) a descreve originalmente como saprófita sobre material vegetal em decomposição e, provavelmente, sobre exúvia de inseto e Sparrow \& Lange (1976), além de ecdise de cobra, ainda citam sua ocorrência em grãos de pólen. A primeira observação da espécie no Brasil é de A.I. Milanez, que a isolou de amostras de solo, coletadas no Estado São Paulo (Pires-Zottarelli \& Gomes 2007).

\section{Chave para as espécies de Rhizophydium}

1. Sistema rizoidal com pedúnculo extramatrical R. stipitatum

1. Sistema rizoidal sem pedúnculo extramatrical

2. Zoosporângios angulares na maturidade R. elyensis 

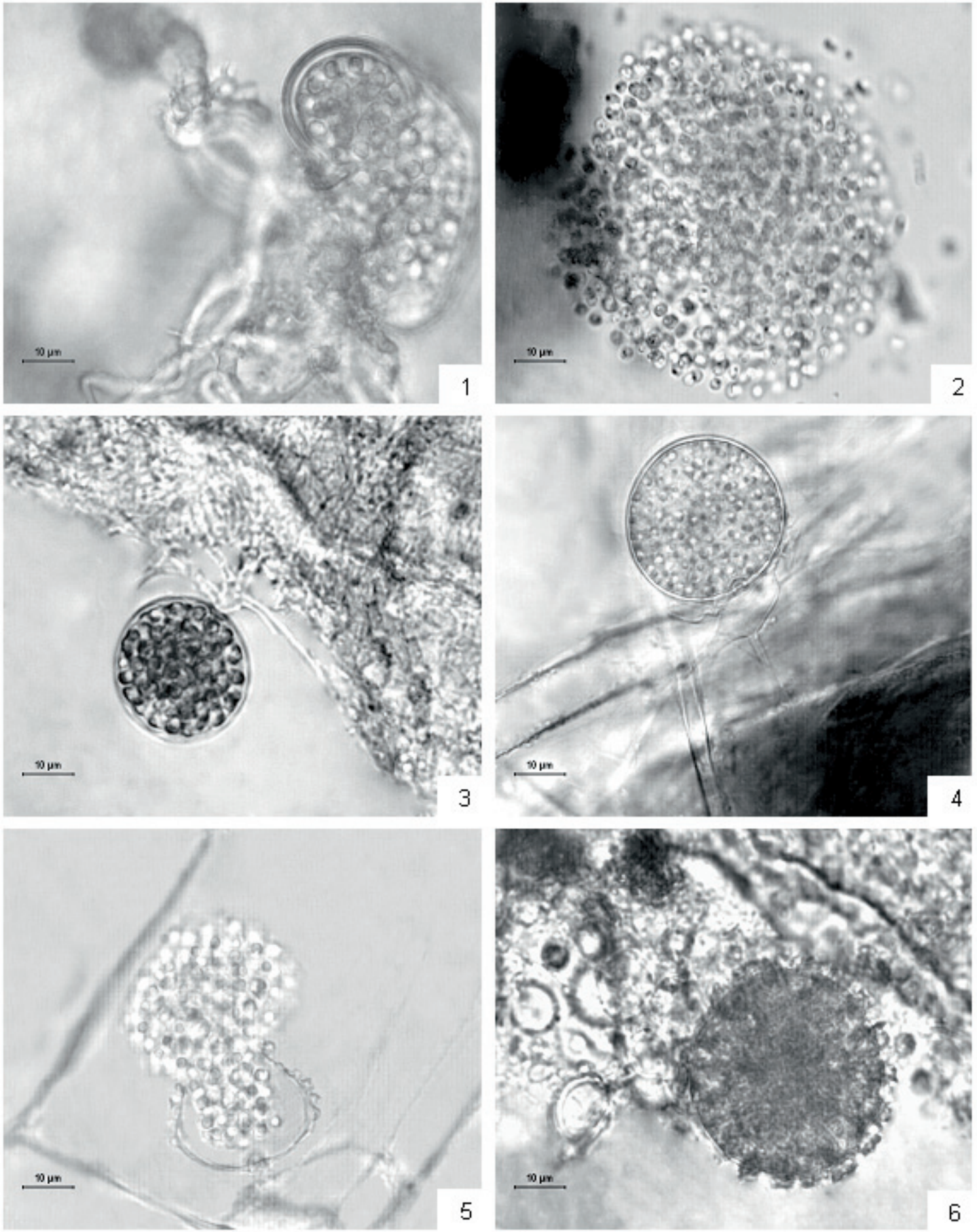

Figuras1-6. 1-2. Chytriomyces appendiculatus Karling. 1. Zoosporângio apendiculado. 2. Zoósporos. 3. Chytriomyces aureus Karling. Zoosporângio não apofisado em exoesqueleto de camarão. 4. Chytriomyces hyalinus Karling. Zoosporângio apofisado. 5. Chytriomyces spinosus Fay. Liberação dos zoósporos. 6. Phlyctochytrium aureliae Ajello. Zoosporângio ornamentado com apófise composta em ecdise de cobra. 
2. Zoosporângios não angulares na maturidade R. macroporosum

Rhizophydium elyensis Sparrow, Trans. Brit. Mycol. Soc. 40: 523-535. 1957.

Fig. 7

Talo eucárpico, monocêntrico, extra-intramatrical. Zoosporângios hialinos, inoperculados, esféricos, 15-50 um diâm., angulares na maturidade; parede lisa, não espessada; 2-8 poros. Sistema rizoidal ramificado, com rizóides delicados saindo de um único eixo principal na base do zoosporângio; sem pedúnculo extramatrical. Zoósporos com uma gotícula lipídica, liberados simultaneamente por meio de poros. Esporos de resistência não observados.

Material examinado: BRASIL. São Paulo: São Paulo, Parque Estadual da Serra da Cantareira, amostras de solo, 11/VIII/2005, 19/X/2005, 26/I/2006, 22/II/2006, 31/III/2006, 19/V/2006, 5/VI/2006, em ecdise de cobra, C.A. Nascimento 381615 (SP).

Distribuição no Brasil: Amazonas: Manaus (M.I.L. Silva, dados não publicados); Piauí: Parque Nacional de Parque Nacional de Sete Cidades (Rocha 2006); São Paulo: Brotas-Itirapina (Pires-Zottarelli \& Milanez 1993), Cubatão (Shoenlein-Crusius et al. 2006), Santo André (Schoenlein-Crusius et al. 1992; Schoenlein-Crusius \& Milanez 1998) e São Paulo (Pires-Zottarelli et al. 1996; Rocha \& Pires-Zottarelli 2002).

Os zoosporângios apresentaram-se maiores que os descritos originalmente por Sparrow (1957), de 23-25 um diâm., e concordam com Pires-Zottarelli \& Milanez (1993), os quais citam de (8-)13-31(-46) $\mu \mathrm{m}$ diâm. A espécie apresentou crescimento sapróbio apenas em substrato queratinoso, ecdise de cobra, concordando com Sparrow (1957). Foi relatada pela primeira vez no Brasil por Pires-Zottarelli \& Milanez (1993), que a isolaram de amostras de água e solo, iscadas com palha de milho, grãos de pólen e ecdise de cobra, coletadas em Brotas-Itirapina, SP.

Rhizophydium macroporosum Karling, Sydowia 20: 74-85. 1967.

Fig. 8

Talo eucárpico, monocêntrico, extra-intramatrical. Zoosporângios de hialinos a marrons, predominantemente esféricos, 14-47,5 $\mu \mathrm{m}$ diâm.; 1-6 papilas cônicas, bastante protuberantes, com 3-6 $\mu \mathrm{m}$ de altura; base larga, 8-22,5 $\mu \mathrm{m}$ de larg.; zona clara de matriz gelatinosa logo abaixo das papilas; parede lisa, espessada; faixa na base da papila com a extremidade ocasionalmente apresentando um aspecto desgastado ou denteado. Sistema rizoidal ramificado, extensivo, um eixo principal saindo da base do zoosporângio; eixo principal 2,5-9 $\mu \mathrm{m}$ de espessura; constrições às vezes presentes; pedúnculo extramatrical ausente. Zoósporos com uma gotícula lipídica, liberados simultaneamente por meio dos poros, envolvidos por uma matriz gelatinosa hialina onde permanecem agrupados antes de sua dispersão. Esporos de resistência não observados.

Material examinado: BRASIL. São Paulo: São Paulo, Parque Estadual da Serra da Cantareira, amostras de solo, 11/VIII/2005, 7/XII/2005, 22/II/2005, em ecdise de cobra, C.A. Nascimento 381616 (SP).

A espécie foi descrita, originalmente, por Karling (1967), que a isolou de amostras de solo, iscadas com substrato queratinoso (ecdise de cobra) e celulósico (palha de milho), coletadas na Nova Zelândia. Os zoosporângios dos espécimes estudados apresentaramse menores que os descritos pelo autor, que cita de 30-140 $\mu \mathrm{m}$. Trata-se da primeira citação para o Brasil.

Rhizophydium stipitatum Sparrow, Trans. Brit. Mycol. Soc. 40: 528. 1957.

Fig. 9

Talo eucárpico, monocêntrico, extra-intramatrical. Zoosporângios hialinos, esféricos, 10-60 um diâm.; parede lisa, não espessada; com 1-6 poros. Sistema rizoidal extensivo, com um pedúnculo extramatrical saindo da base do zoosporângio. Zoósporos com uma gotícula lipídica hialina, liberados simultaneamente por meio dos poros. Esporos de resistência não observados.

Material examinado: BRASIL. São Paulo: São Paulo, Parque Estadual da Serra da Cantareira, amostras de água, 8/VI/2005, 7/XII/2005, e de solo, 21/IX/2005, 8/VI/2005 19/X/2005 e 26/I/2006, em ecdise de cobra, C.A. Nascimento 393252 (SP).

Distribuição no Brasil: Amazonas: Manaus (M.I.L. Silva, dados não publicados); Piauí: Parque Nacional de Sete Cidades (Rocha 2006); São Paulo: Assis (Milanez 1984), Brotas-Itirapina (Pires-Zottarelli \& Milanez 1993) e Santo André (Schoenlein-Crusius et al. 1992; Schoenlein-Crusius \& Milanez 1998).

Os zoosporângios apresentaram-se menores que os citados por Sparrow (1957) que, em descrição original,

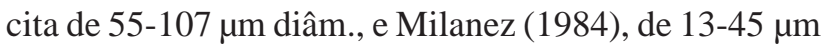
diâm. A espécie foi observada apenas em ecdise de cobra, concordando com Sparrow (1957), no entanto, Milanez (1984) ainda relata seu crescimento em substrato celulósico, grãos de pólen, sendo esta referência a primeira citação da espécie para o Brasil, isolada de amostras de solo coletadas em Assis, Estado de São Paulo.

Septosperma rhizophydii Whiffen ex W.H. Blackw. \& M.J. Powell, Mycotaxon 42: 45. 1991.

Fig. 10 
Talo parasítico, eucárpico, monocêntrico. Zoosporângios hialinos, inoperculados, piriformes, 8-15×6-12,5 $\mu \mathrm{m}$; parede lisa; poro de liberação único. Sistema rizoidal ausente; com haustórios; com ou sem pedúnculo. Zoósporos com uma gotícula lipídica hialina, liberados através do poro inconspícuo formado na parede do zoosporângio. Esporos de resistência cilíndricos, 10-22,5×3-5 $\mu \mathrm{m}$, com ou sem pedúnculo; porção fértil na região apical, com numerosas gotículas lipídicas; germinação não observada.

Material examinado: BRASIL. São Paulo: São Paulo, Parque Estadual da Serra da Cantareira, amostras de solo, 8/VI/2005, 6/VII/2005, 11/VIII/2005, 21/IX/2005, 19/X/2005 e 19/V/2006, parasita em Entophlyctis luteolus Longcore e Rhizophydium sp., em amostras de solo, C.A. Nascimento 381617 (SP).

Distribuição no Brasil: São Paulo: São Paulo (Milanez 1974; Milanez et al. 1994).

As características dos espécimes examinados concordam com a descrição original de Whiffen (1942). Foi observada parasitando zoosporângios de Rhizophydium sp. e Entophlyctis luteolus, no entanto, outros hospedeiros são citados em literatura, como Rhizophydium macrosporum Karling, Rhizophydium spp., Rhizidium richmondense Willoughby, Rhizophlyctis sp. e Rhizidiomyces apophysatus Zopf (Whiffen 1942; Willoughby 1965; Seymour 1971). Foi relatada pela primeira vez no Brasil por Milanez (1974) que a isolou como parasita de zoosporângios de Rhizophydium sp. em amostras de solo, iscadas com grãos de pólen, coletadas no município de São Paulo, Estado de São Paulo.

Solutoparies pythii Whiffen ex Blackwell. \& Powell, Mycotaxon 67: 465. 1998.

Fig. 11-12

Talo parasítico, eucárpico, monocêntrico. Zoosporângios hialinos, inoperculados, esféricos,

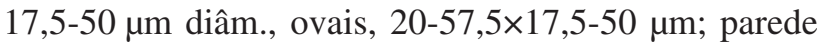
com ornamentações espinhosas não bifurcadas, cônicas e curtas. Rizóides ramificados, saindo de um eixo principal na base do zoosporângio e aderidos à hifa do hospedeiro; eixo principal tornando-se inflado como uma apófise na maturidade. Zoósporos com uma gotícula lipídica hialina, liberados após a dissolução da parede do zoosporângio, exceto na parte basal, e envolvidos por uma matriz gelatinosa, onde permanecem por um breve período antes de sua dispersão. Esporos de resistência não observados.

Material examinado: BRASIL. São Paulo: São Paulo, Parque Estadual da Serra da Cantareira, amostras de água, 26/I/2006, parasita em Pythium sp. em amostra de água, C.A. Nascimento.
Os zoosporângios ovais do espécime observado se apresentaram menores que os citados por Whiffen (1942), de 16,4-80,3×14,3-68,4 $\mu \mathrm{m}$, concordando com as demais características citadas pela autora. $\mathrm{O}$ gênero e a espécie foram originalmente descritos por Whiffen (1942), mas não foram validamente publicados devido à ausência da diagnose latina e citação do tipo. Posteriormente, Blackwell \& Powell (1998) validaram nomenclaturalmente e tipificaram o gênero e a espécie. Devido à contaminação, os espécimes não se preservaram. Solutoparies pythii foi primeiramente isolada parasitando Pythium sp., em amostras coletadas nos E.U.A. Trata-se da primeira citação para o Brasil.

\section{CLADOCHYTRIACEAE}

\section{Chave para as espécies de Cladochytrium}

1. Zoosporângios ornamentados C. setigerum

1. Zoosporângios lisos

2. Esporos de resistência com um gló-

bulo lipídico dourado. C. replicatum

2. Esporos de resistência com um glóbulo lipídico hialino C. tепие

Cladochytrium replicatum Karling, Amer. J. Bot. 18: 526-557. 1931.

Fig. 13-14

Talo eucárpico, policêntrico, intramatrical. Rizomicélio extensivo, delicado e bastante ramificado; células turbinadas intercalares, septadas, formadas em intervalos regulares. Zoosporângios hialinos, inoperculados, esféricos, 7,5-15 $\mu \mathrm{m}$ diâm, ovais ou piriformes e ocasionalmente fusiformes; geralmente terminais; parede lisa; tubo de liberação ou papila únicos, variáveis em tamanho; com ou sem apófise. Zoósporos com uma conspícua gotícula lipídica dourada, liberados por meio de um poro formado no ápice do tubo de liberação ou de uma papila, permanecendo agrupados por um breve período, antes de sua dispersão. Esporos de resistência intercalares, esféricos, 10-17,5 $\mu$ m diâm.; parede lisa, espessada; com um conspícuo glóbulo lipídico dourado; germinação não observada.

Material examinado: BRASIL. São Paulo: São Paulo, Parque Estadual da Serra da Cantareira, amostras de água, 8/VI/2005, 6/VII/2005, 11/VIII/2005, 21/IX/2005, 17/XI/2005, 7/XII/2005, 26/I/2006, 22/II/2006, 31/III/2006, 19/V/2006 e 5/VI/2006, e de solo, 8/VI/2005, 11/VIII/2005, 21/IX/2005, 19/X/2005, 17/XI/2005, 7/XII/2005 e 22/II/2006, em epiderme de cebola e palha de milho, C.A. Nascimento 381618 (SP).

Distribuição no Brasil: Acre: (Karling 1945a); Amazonas: Manaus (Karling 1945a; M.I.L. Silva, 

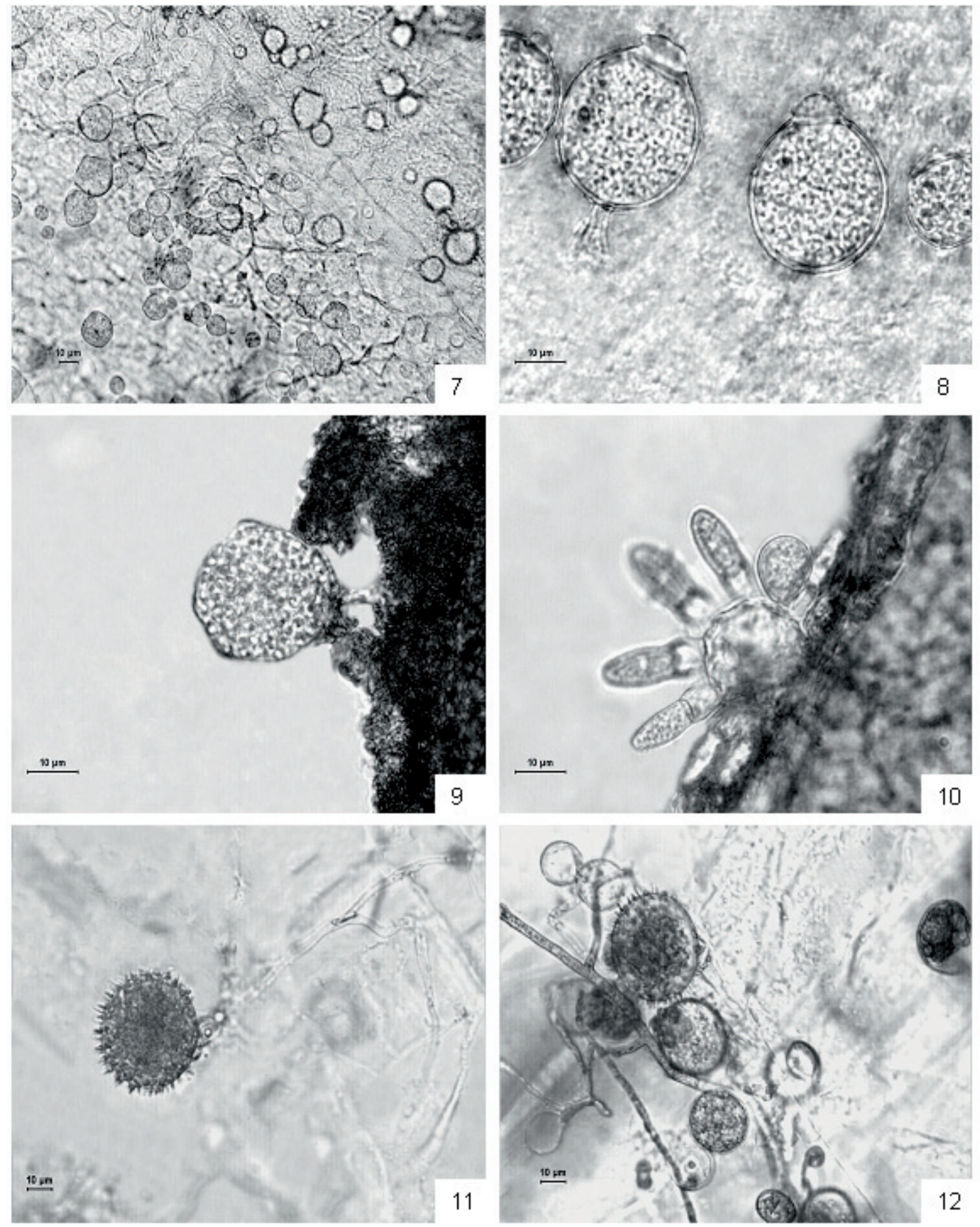

Figuras 7-12. 7. Rhizophydium elyensis Sparrow. Zoosporângios em ecdise de cobra. 8. Rhizophydium macroporosum Karling. Zoosporângios com parede espessada e papila conspícua. 9. Rhizophydium stipitatum Sparrow. Zoosporângio com pedúnculo extramatrical em ecdise de cobra. 10. Septosperma rizophydii Whiffen ex W.H. Blackwell. \& M.J. Powell. Zoosporângios e esporos de resistência em Rhizophydium sp. 11-12. Solutoparies pythii Whiffen ex W.H. Blackwell. \& M.J. Powell. 11. Zoosporângio com ornamentações espinhosas. 12. Zoosporângios parasitando Pythium sp. 
dados não publicados); Ceará: (Karling 1945a); Mato Grosso: (Karling 1945a). Minas Gerais: Ingaí (J.M. Oliveira, dados não publicados); Pernambuco: Recife (M.S. Cavalcanti, dados não publicados); Piauí: Parque Nacional de Sete Cidades (Rocha 2006); Rondônia: São Carlos (Karling 1944b); São Paulo: Brotas-Itirapina (Pires-Zottarelli \& Milanez 1993), Cubatão (Schoenlein-Crusius et al. 2006), Itapecerica da Serra (Schoenlein-Crusius et al. 1990), Riacho Grande (Rogers et al. 1970), Santo André (Schoenlein-Crusius \& Milanez 1998); e São Paulo (Pires-Zottarelli et al. 1996; Rocha \& Pires-Zottarelli 2002; Pires-Zottarelli \& Rocha 2007).

Os zoosporângios dos espécimes estudados se apresentaram pouco menores que os descritos originalmente por Karling (1931), que cita de 8-18 $\mu \mathrm{m}$ diâm., e Pires-Zottarelli (1993), de 9-17 $\mu$ m diâm. Cladochytrium replicatum foi observada apenas em substratos celulósicos, epiderme de cebola e palha de milho, no entanto, Karling (1931) a isolou como parasita de várias plantas aquáticas. A espécie foi isolada pela primeira vez no Brasil por Karling (1945a), de amostras de água coletadas nos Estados do Acre, Mato Grosso, Amazonas e Ceará.

Cladochytrium setigerum Karling, Bulletin of Torrey Botanical Club 78: 38-43. 1951.

Fig. 15-16

Talo eucárpico, policêntrico, intramatrical. Rizomicélio extensivo, delicado e muito ramificado; células turbinadas intercalares, geralmente alongadas ou de formas irregulares. Zoosporângios hialinos, inoperculados, geralmente esféricos, 7-12,5 $\mu \mathrm{m}$ diâm.; terminais ou intercalares; parede com ornamentações em forma de setas simples ou ramificadas; tubo de liberação ou papila não observados; sem apófise. Zoósporos com uma gotícula lipídica hialina, liberação não observada. Esporos de resistência intercalares, variáveis em forma, predominantemente esféricos, 8-18 $\mu \mathrm{m}$ diâm., ovais, piriformes, alongados e irregulares; parede com ornamentações em forma de setas simples ou ramificadas, espessada; com um grande glóbulo lipídico hialino; germinação não observada.

Material examinado: BRASIL. São Paulo: São Paulo, Parque Estadual da Serra da Cantareira, amostras de água, 7/XII/2005, 31/III/2006, e de solo, 11/VIII/2005, 21/IX/2005, 17/XI/2005, 22/II/2006, em epiderme de cebola, C.A. Nascimento 381619 (SP).

Os zoosporângios esféricos dos espécimes examinados se apresentaram menores que os descritos originalmente por Karling (1951), 13,2-28,5 $\mu \mathrm{m}$ diâm., isolados de amostras de solo, iscadas com substrato celulósico, coletadas em
Maryland, EUA, concordando com as demais características mencionadas pelo autor. Trata-se da primeira citação da espécie para o Brasil.

Cladochytrium tenue Nowakowski, Cohn. Beitr. Biol. Pflanzen 2: 92. 1876.

Fig. 17-18

Talo eucárpico, policêntrico, intramatrical. Rizomicélio extensivo, delicado e muito ramificado; células turbinadas intercalares, esféricas, 10-20 $\mu \mathrm{m}$ diâm., ovais, 7,5-15×5-13 $\mu \mathrm{m}$, às vezes alongadas ou fusiformes. Zoosporângios não observados. Esporos de resistência intercalares, esféricos, 7,5-17,5 $\mu \mathrm{m}$ diâm.; parede lisa, espessada; geralmente com apófise; com um conspícuo glóbulo lipídico hialino; germinação não observada.

Material examinado: BRASIL. São Paulo: São Paulo, Parque Estadual da Serra da Cantareira, amostras de água, 8/VI/2005, 6/VII/2005, 21/IX/2005 e de solo, 8/VI/2005, 11/II/2005, 17/XI/2005, 26/I/2006, 22/II/2006, 31/III/2006, em epiderme de cebola, C.A. Nascimento 393250 (SP).

Distribuição no Brasil: Amazonas: Manaus (M.I.L. Silva, dados não publicados, Karling 1945a); Mato Grosso: (Karling 1946); Piauí: Parque Nacional de Sete Cidades (Rocha 2006); Rondônia: Porto Velho e São Carlos (Karling 1945a); São Paulo: São Paulo (PiresZottarelli \& Gomes 2007).

Os espécimes examinados apresentaram células turbinadas ovais um pouco maiores que as descritas por Karling (1945a), que as cita com 9-12×6-8 $\mu$ ma primeira citação da espécie no Brasil, isolada de amostras de água e solo, iscadas com substratos celulósicos, epiderme de cebola e palha de milho, coletadas nos Estados do Mato Grosso e Amazonas.

\section{Chave para as espécies de Nowakowskiella}

1. Esporos de resistência ausentes N. elegans

1. Esporos de resistência presentes .......... multispora

Nowakowskiella elegans (Nowak.) Schroeter, Engler and Prantl, Natürlichen Pflanzenfam. 1: 82. 1892/ 1893.

Basiônimo: Cladochytrium elegans Nowak., pro parte, in Cohn, Beitr. Biol. Pflanzen 2: 95. 1876.

Fig. 19

Talo eucárpico, policêntrico, extra-intramatrical. Rizomicélio extensivo e ramificado; dilatações intercalares, não septadas. Zoosporângios hialinos, operculados, esféricos, 12,5-25 um diâm., piriformes, 15-35×12,5-30 $\mu \mathrm{m}$; parede lisa; tubo de liberação ou 

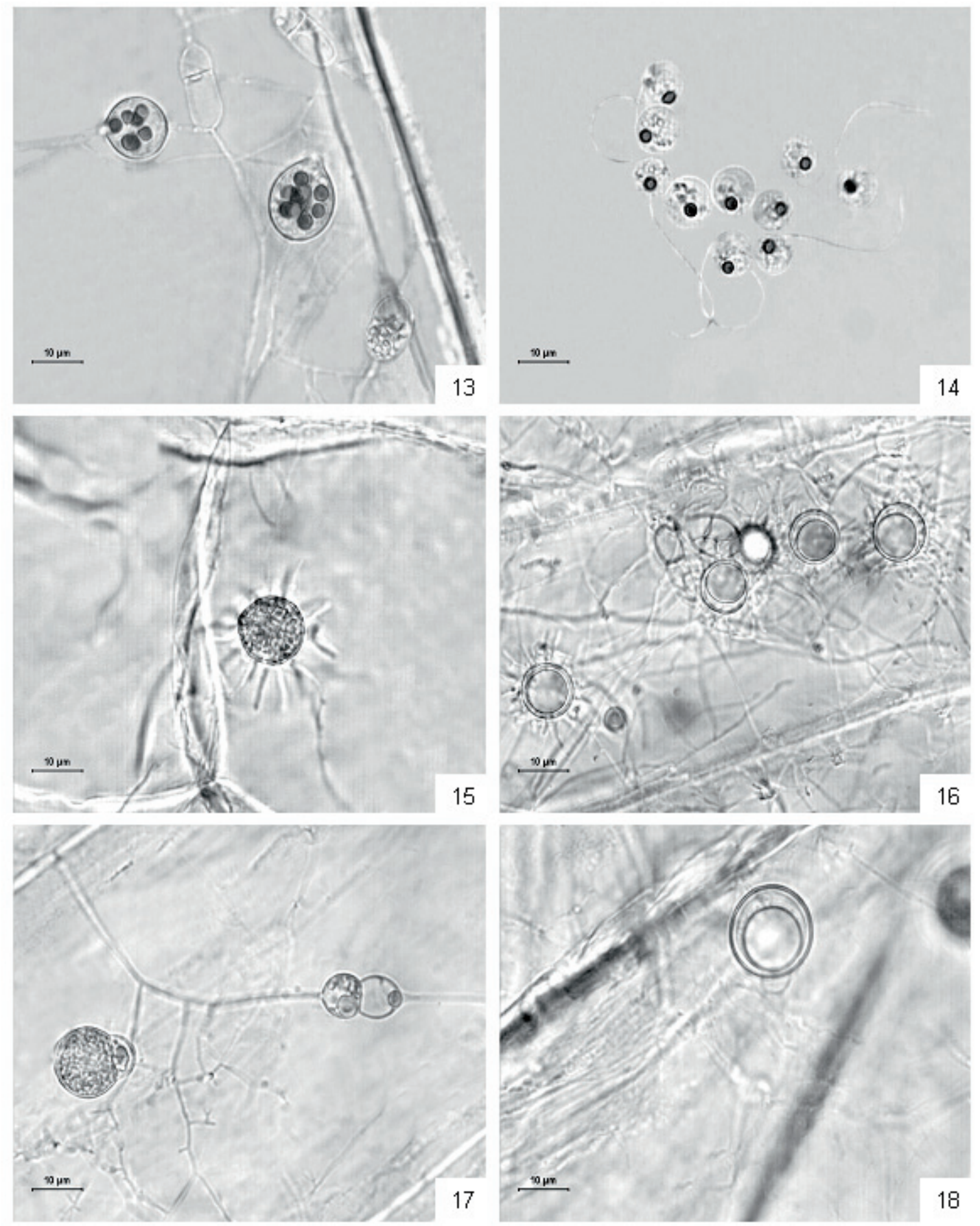

Figuras 13-18. 13-14. Cladochytrium replicatum Karling. 13. Talo policêntrico evidenciando zoosporângios e células turbinadas. 14. Zoósporos. 15-16. Cladochytrium setigerum Karling. 15. Zoosporângio ornamentado. 16. Esporos de resistência. 17-18. Cladochytrium tenue Karling. 17. Talo policêntrico com células turbinadas. 18. Esporo de resistência. 
papila únicos, geralmente curtos; com ou sem apófise. Zoósporos com uma gotícula lipídica hialina, liberados por meio de opérculo formado no ápice do tubo de liberação ou de uma papila, permanecendo agrupados por um breve período antes de sua dispersão. Esporos de resistência não observados.

Material examinado: BRASIL. São Paulo: São Paulo, Parque Estadual da Serra da Cantareira, amostras de água, 8/VI/2005, 11/VIII/2005, 21/IX/2005, 17/XI/2005 e 22/II/2006, e de solo, 8/VI/2005, 11/VIII/2005, 21/IX/2005, 19/X/2005, 31/III/2006 e 5/VI/2006, em epiderme de cebola e palha de milho, C.A. Nascimento 381620 (SP).

Distribuição no Brasil: Amazonas: Manaus (M.I.L. Silva, dados não publicados); Paraíba: Areia (Joffily 1947); Pernambuco: Recife (M.S. Cavalcanti, dados não publicados); Piauí: Parque Nacional de Sete Cidades (Rocha 2006); Rondônia: São Carlos (Karling 1944a); São Paulo: Assis, Presidente Epitácio, Santo Anastácio (Milanez 1984), Brotas-Itirapina (Pires-Zottarelli \& Milanez 1993), Cubatão (Schoenlein-Crusius et al. 2006), Itapecerica da Serra (Schoenlein-Crusius et al. 1990), Riacho Grande (Lyra \& Milanez 1974), Santo André (Schoenlein-Crusius et al. 1992; SchoenleinCrusius \& Milanez 1998) e São Paulo (SchoenleinCrusius \& Milanez 1989; Pires-Zottarelli et al. 1996; Rocha \& Pires-Zottarelli 2002).

As características dos espécimes examinados concordam com as monografias de Sparrow (1960) e Karling (1977). A primeira citação no Brasil é de Karling (1944a), que a isolou de amostras de solo, coletadas no Mato Grosso do Sul, e de amostras de água e solo coletadas em Manaus, Estado do Amazonas.

Nowakowskiella multispora Karling, Sydowia 17: 314-315. 1964.

Fig. 20

Talo eucárpico, policêntrico, extra-intramatrical. Rizomicélio extensivo, ramificado; dilatações intercalares geralmente ovóides, fusiformes ou alongadas. Zoosporângios hialinos, operculados, esféricos,

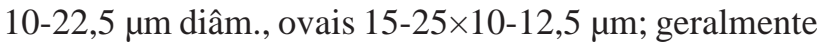
terminais; parede lisa; tubo de liberação ou papila únicos, variáveis em tamanho; sem apófise. Zoósporos com uma gotícula lipídica hialina, liberados por meio do opérculo formado no ápice do tubo de liberação ou papila. Esporos de resistência intercalares, ovais, 15-20×7,5-15 $\mu \mathrm{m}$, às vezes alongados; parede lisa, espessada; com várias gotículas lipídicas; germinação não observada.

Material examinado: BRASIL. São Paulo: São Paulo, Parque Estadual da Serra da Cantareira, amostras de água, 19/X/2005, 17/XI/2005, 19/V/2006 e 5/VI/2006, e de solo, 19/X/2005 e 27/IV/2006, em epiderme de cebola e celofane, C.A. Nascimento 381621 (SP).
Distribuição no Brasil: Minas Gerais: Ingaí (J.M. Oliveira, dados não publicados); São Paulo: Cubatão (Schoenlein-Crusius et al. 2006) e São Paulo (Rocha \& Pires-Zottarelli 2002).

As características dos espécimes observadas concordam com a descrição original de Karling (1964). A espécie apresentou crescimento apenas em substratos celulósicos, epiderme de cebola e celofane, concordando com Karling (1964) e Rocha \& Pires-Zottarelli (2002) que ainda relatam o seu crescimento em palha de milho. A espécie foi isolada pela primeira vez no Brasil de amostras de água, iscadas com epiderme de cebola e celofane, coletadas em Cubatão, Estado de São Paulo (Schoenlein-Crusius et al. 2006).

Septochytrium willoughbyi Dogma, Nova Hedwigia 24: 367-377. 1973.

Fig. 21

Talo eucárpico, policêntrico, intramatrical. Rizomicélio extensivo, muito ramificado; dilatações alongadas ou fusiformes; septos formados apenas para delimitação das estruturas reprodutivas. Zoosporângios hialinos, operculados, esféricos, 17,5-37 $\mu$ m diâm., ovais, $20-37,5 \times 17,5-27,5 \mu \mathrm{m}$; parede lisa em zoosporângios jovens, tornando-se rugosa na maturidade; papila proeminente ou tubo de liberação único, muito variável em tamanho, ocasionalmente ramificado. Zoósporos com várias gotículas lipídicas hialinas, liberados por meio da abertura do opérculo formado no ápice do tubo de liberação ou de uma papila, permanecendo agrupados por um breve período antes de sua dispersão. Esporos de resistência intercalares, marrons, esféricos, 27,5-32,5 um diâm., às vezes ovais; parede espessada, com pequenas protuberâncias; com vários glóbulos lipídicos e um vacúolo central; germinação não observada.

Material examinado: BRASIL. São Paulo: São Paulo, Parque Estadual da Serra da Cantareira, amostras de água, 6/VII/2005, 21/IX/2005, 17/XI/2005, 26/I/2006 e 22/II/2006, e de solo, 8/VI/2005, 6/VII/2005, 11/VIII/2005, 21/IX/2005, 19/X/2005, 7/XII/2005, 26/I/2006, 22/II/2006, 31/III/2006, 27/IV/2006 e 19/V/2006, em epiderme de cebola e palha de milho, C.A. Nascimento 381622 (SP).

Distribuição no Brasil: Minas Gerais: Ingaí (J.M. Oliveira, dados não publicados); Piauí: Parque Nacional de Sete Cidades (Rocha 2006); Rondônia: (Dogma 1973).

As características dos espécimes examinados concordam parcialmente com a descrição original de Dogma (1973), na primeira citação da espécie para o Brasil, isolada de amostras de solo, iscadas com epiderme de cebola e celofane no Estado de Rondônia. Os 
zoosporângios esféricos se apresentaram menores que os descritos pelo autor, que menciona de 23-56 $\mu \mathrm{m}$ diâm., e os esporos de resistência esféricos foram maiores que os por ele descritos, de 10-20 $\mu$ m diâm. O autor cita a presença de talo monocêntrico apendiculado, policêntrico não apendiculado e, rizomicélio trabeculado a raramente septado para seus isolados, características não observadas neste estudo. Trata-se da primeira citação da espécie para o Estado de São Paulo.

\section{ENDOCHYTRIACEAE}

Chave para as espécies de Diplophlyctis

1. Zoosporângios lisos . D. intestina

1. Zoosporângios ornamentados D. sarcoptoides

Diplophlyctis intestina (Schenk) Schroeter, Engler and Prantl, Natürlichen Pflanzenfam. 1: 78. 1892.

Fig. 22

Talo eucárpico, monocêntrico, extra-intramatrical. Zoosporângios hialinos, inoperculados, esféricos a subesféricos, 17,5-75 $\mu$ m diâm.; parede lisa; tubo de descarga único, geralmente longo; apófise predominantemente esférica, às vezes irregular, variável em tamanho. Sistema rizoidal extensivo, muito ramificado, saindo de um eixo principal na base da apófise. Zoósporos com uma gotícula lipídica hialina, liberados por meio de um poro formado no ápice do tubo de liberação, geralmente permanecendo agrupados, por um breve período, antes da sua dispersão. Esporos de resistência marrons, esféricos, 22-30 $\mu \mathrm{m}$ diâm., parede espessada com pequenas ornamentações em forma de espinhos agudos, conteúdo granular; apófise presente; germinação não observada.

Material examinado: BRASIL. São Paulo: São Paulo, Parque Estadual da Serra da Cantareira, amostras de água, 8/VI/2005 e 19/V/2006, e amostras de solo, 19/X/2005, 19/V/2006, em epiderme de cebola, C.A. Nascimento.

Os zoosporângios observados se apresentaram menores que os descritos por Sparrow (1960), que cita acima de 80 1/4m diâm., concordando com as demais características relatadas pelo autor. Nenhuma evidência da formação de esporos de resistência precedida por reprodução sexuada, semelhante à observada por Sparrow (1936), foi encontrada nos isolados obtidos neste estudo. Em suas observações, o autor relata a nítida conexão entre os rizóides de diferentes talos e algumas vezes do rizóide de um talo com a apófise ou ponto de origem dos rizóides de um outro talo. A preparação de lâmina semi-permanente não se mostrou eficiente para preservação dos espécimes. A espécie foi primeiramente descrita por A. Schenk, ocorrendo como sapróbia ou como um fraco parasita em Nitella flexilis (L.) Ag., isolada de amostras coletadas na Alemanha (Sparrow 1960). Trata-se da primeira citação para o Brasil.

Diplophlyctis sarcoptoides (H.E. Petersen) Dogma, Nova Hedwigia 25: 122-123. 1974.

Basiônimo: Asterophlyctis sarcoptoides H.E. Petersen, J. Bot. 17: 218. 1963.

Fig. 23-24

Talo monocêntrico, eucárpico, extra-intramatrical. Zoosporângios hialinos, inoperculados, esféricos ou subesféricos, 15-27,5 $\mu \mathrm{m}$ diâm., ovais, 17-37×11-32 $\mu \mathrm{m}$, ocasionalmente irregulares; parede com ornamentações em forma de tubérculos, espinhos ou papilas; sem tubo de liberação; apófise esférica. Sistema rizoidal extensivo, muito ramificado, com um a vários eixos saindo da base da apófise. Zoósporos com uma gotícula lipídica hialina, liberados por meio de um poro formado na parede do zoosporângio e envolvidos por uma matriz gelatinosa, onde permanecem agrupados por um breve período antes de sua dispersão. Esporos de resistência hialinos, esféricos ou subesféricos, 14-20 $\mu \mathrm{m}$ diâm., ovais, $17-25 \times 15-20 \mu \mathrm{m}$, às vezes irregulares; parede com ornamentações em forma de tubérculos, espinhos ou papilas, espessada; com vários glóbulos lipídicos e um vacúolo central; apófise esférica; germinação não observada.

Material examinado: BRASIL. São Paulo: São Paulo, Parque Estadual da Serra da Cantareira, amostras de água, 8/VI/2005, 11/VIII/2005, 7/XII/2005, 22/II/2006, 27/IV/2006, 5/VI/2006, e de solo, 21/IX/2005, 17/XI/2005, 7/XII/2005, 27/IV/2006 e 19/V/2006, em exoesqueleto de camarão, C.A. Nascimento 381623 (SP).

Distribuição no Brasil: Amazonas: Manaus (M.I.L. Silva, dados não publicados); Minas Gerais: Ingaí (J.M. Oliveira, dados não publicados); Rondônia: São Carlos (Karling 1945b); São Paulo: Assis (Milanez 1984), Brotas-Itirapina (Pires-Zottarelli \& Milanez 1993); Cubatão (Schoenlein-Crusius et al. 2006), Itapecerica da Serra (Schoenlein-Crusius et al. 1990), Santo André (Schoenlein-Crusius et al. 1992) e São Paulo (PiresZottarelli et al. 1996; Rocha \& Pires-Zottarelli 2002; Pires-Zottarelli \& Rocha 2007).

Os espécimes examinados concordam parcialmente com a descrição original de Dogma (1974) que menciona a ocorrência de zoosporângios lisos, não observados neste estudo. Os zoosporângios ovais apresentaram medidas aproximadas das citadas pelo autor, de 9-39×6-32 $\mu \mathrm{m}$, e zoosporângios esféricos pouco menores que os relatos por Rocha \& Pires-Zottarelli

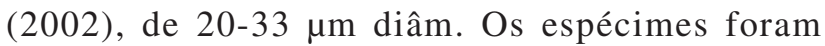



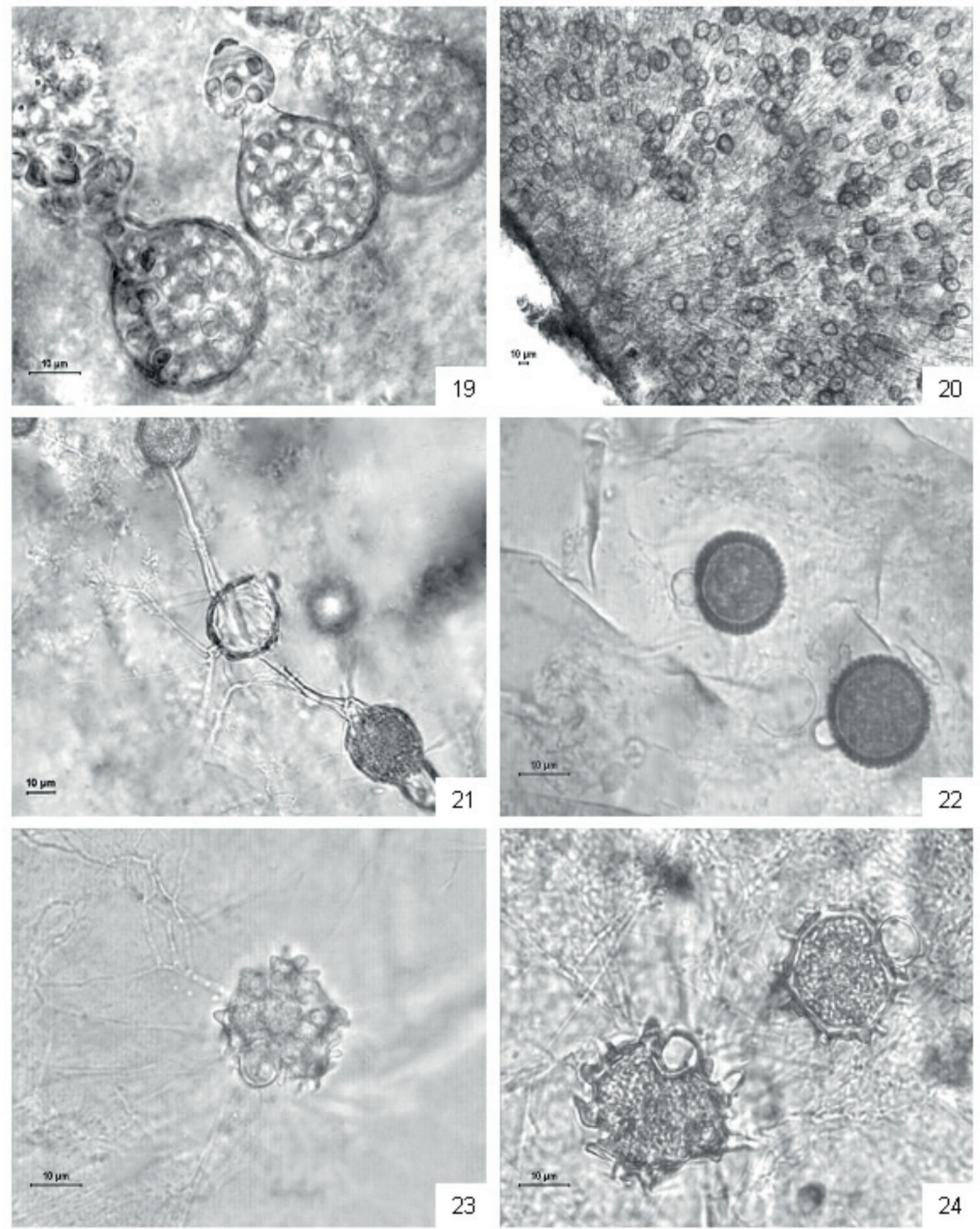

Figura 19-24. 19. Nowakowskiella elegans (Nowak.) Schroeter. Liberação de zoósporos dos zoosporângios. 20. Nowakowskiella multispora Karling. Talo policêntrico evidenciando os esporos de resistência intercalares em celofane. 21. Septochytrium willoughbyi Dogma. Talo policêntrico com zoosporângios operculados. 22. Diplophlyctis intestina (Shenk.) J. Schroeter. Esporos de resistência apofisados e ornamentados. 23-24. Diplophlyctis sarcoptoides (H.E. Petersen) Dogma. 23. Zoosporângio. 24. Esporos de resistência. 
observados crescendo em substrato quitinoso, exoesqueleto de camarão, concordando com Dogma (1974) e Rocha \& Pires-Zottarelli (2002). A primeira citação deste gênero no Brasil com o nome Asterophlyctis é de Karling (1945b), no entanto, a espécie A. sarcoptoides H.E. Petersen só foi referida por Antikajian (1949) a partir do espécime fornecido por J.S. Karling, isolado de amostras de solo coletadas no Estado de Rondônia (Milanez 1984). Baseado em observações do desenvolvimento do talo de A. sarcoptoides Dogma (1974) transferiu a espécie para o gênero Diplophlyctis.

Entophlyctis luteolus Longcore, Mycologia 87: 25-33. 1995.

Entophlyctis luteolus caracteriza-se pela formação de zoosporângios inoperculados com 1-4 eixos rizoidais, cisto do zoósporo persistindo no rizóide e, principalmente, pela presença de esporos de resistência com parede interna e/ou externa lisa ou irregular, apresentando uma típica coloração amarelada. Foi isolada de amostras de água e solo iscadas com substratos celulósicos, epiderme de cebola e palha-de-milho. A descrição completa da espécie consta em Pires-Zottarelli et al. (2007).

Ao longo do estudo, Chytriomyces appendiculatus Karling e $C$. aureus Karling apresentaram maior frequiência de ocorrência (100\%), enquanto Chytriomyces spinosus Fay, Phlyctochytrium aureliae Ajello e Solutoparies pythii Whiffen ex W.H. Blackwell \& M.J. Powell foram menos freqüentes $(7,7 \%)$, ocorrendo uma única vez. Embora a maioria das espécies encontradas tenha sido comum nos dois compartimentos, Chytriomyces spinosus Fay e Solutoparies pythii ocorreram apenas em amostras de água, enquanto Phlyctochytrium aureliae Ajello, Rhizophydium elyensis Sparrow, R. macroporosum Karling e Septosperma rhizophydii Whiffen ex W.H. Blackwell \& M.J. Powell foram exclusivas de amostras de solo (Tab. 1).

Por se tratar do primeiro estudo com Chytridiales realizado no Parque Estadual da Serra da Cantareira, os resultados obtidos contribuem de maneira significativa para o conhecimento da micota local, e ampliam o conhecimento do grupo em áreas de Mata Atlântica no Estado de São Paulo e no Brasil. Sendo este um estudo pontual, quando considerada toda a área do Parque, destaca-se a necessidade de sua conservação para a realização de estudos futuros.

\section{Agradecimentos}

Ao Conselho Nacional de Pesquisa e Desenvolvimento (CNPq), pela concessão de bolsa de
Mestrado à primeira autora e de Produtividade em Pesquisa à segunda autora; ao Instituto de Botânica de São Paulo pela infra-estrutura oferecida para o desenvolvimento do trabalho e ao Instituto Florestal pela autorização concedida para a realização das coletas.

\section{Referências bibliográficas}

Ajello, L. 1945. Phlyctochytrium aureliae parasitized by Rhizophydium chytridiophagum. Mycologia 37: 109-119.

Alexopoulos, C.J.; Mims, C.W. \& Blackwell, M. 1996. Introductory Mycology. $4^{\text {th }}$ ed. New York, Wiley \& Sons.

Booth, T. 1979. Strategies for study of fungi in marine and marine influenced ecosystems. Revista de Microbiologia 10: 123-138.

Blackwell, W.H. \& Powell, M.J. 1998. Nomenclatural validation of Solutoparies (Chytridiomycetes). Mycotaxon 68: 463-467.

Dogma Jr., I.J. 1973. Septochytrium willoughbyi, a new polycentric chytridiomycete with monocentric resting spore thalli. Nova Hedwigia 24: 367-377.

Dogma Jr., I.J. 1974. Studies on chitinophilic Siphonaria, Asterophlyctis and Rhizoclosmatium, Chytridiales. II. Asterophlyctis sarcoptoides H.E. Petersen: a Diplophlyctis with a sexual phase. Nova Hedwigia 25: $1-50$.

Fay, D.J. 1947. Chytriomyces spinosus nov. sp. Mycologia 39: 152-157.

Joffily, I.M. 1947. Alguns ficomicetos aquáticos e terrícolas do Brasil. Boletim da Sociedade Brasileira de Agronomia 10: 95-113.

Karling, J.S. 1931. Studies in Chytridiales VI. The occurrence and life history of a new species of Cladochytrium in cells of Eriocaulon septangulare. American Journal of Botany 18: 526-557.

Karling, J.S. 1944a. Brazilian chytrids. I. Species of Nowakowskiella. Bulletin of the Torrey Botanical Club 71: 374-389.

Karling, J.S. 1944b. Brazilian Chytrids. IV. Species of Rozella. Mycologia 36: 638-647.

Karling, J.S. 1945a. Brazilian chytrids. V. Nowakowskiella macrospora sp., and other polycentric species. American Journal of Botany 32: 29-35.

Karling, J.S. 1945b. Brazilian chytrids. VI. Rhopalophlyctis and Chytriomyces, two new operculate genera. American Journal of Botany 32: 362-369.

Karling, J.S. 1946. Two new chytrid parasites of Chytriomyces. Mycologia 38: 103-109.

Karling, J.S. 1947. New species of Chytriomyces. Bulletin of Torrey Botanical Club 74: 334-344.

Karling, J.S. 1951. Cladochytrium setigerum sp. nov. and Septochytrium marylandicum sp. nov. from Maryland. Bulletin of Torrey Botanical Club 78: 38-43.

Karling, J.S. 1964. Indian chytrids. IV. Nowakowskiella multispora sp. nov. and other polycentric species. Sydowia 17: 314-319.

Karling, J.S. 1967. Some Zoosporic Fungi of New Zealand. III. Phlyctidium, Rhizophydium, Septosperma and Podochytrium. Sydowia, Annales Mycologici 20: 74-85.

Karling, J.S. 1977. Chytridiomycetarum Iconographia. New York, Vaduz: J. Cramer.

Kirk, P.M.; Cannon, P.F.; David, J.C. \& Stalpers, J.A. 2001. Dictionary of Fungi. $9^{\text {th }}$ ed. Surrey CABI Bioscience.

Lyra, N.P. \& Milanez, A.I. 1974. Notas para o levantamento dos ficomicetos aquáticos do Estado de São Paulo. Instituto de Micologia, Universidade Federal de Pernambuco. Publicação 698, pp. 1-27.

Milanez, A.I. 1974. Notes on the genus Septosperma Whiffen ex 
Seymour. Rickia 6: 63-70.

Milanez, A.I. 1984. Fungos zoospóricos do Estado de São Paulo. II. Chytridiomycetes da Região Oeste. Rickia 11: 115-127.

Milanez, A.I. 1989. Fungos de águas continentais. Pp. 17-20. In: O. Fidalgo \& V.L. Bononi (coords.). Técnicas de coleta, preservação e herborização de material botânico. Série Documentos. São Paulo, Instituto de Botânica.

Milanez, A.I.; Pires-Zottarelli, C.L.A. \& Schoenlein-Crusius, I.H. 1994. Fungos aquáticos da região de Mata Atlântica do Estado de São Paulo. ACIESP 2: 142-149.

Pires-Zottarelli, C.L.A. \& Gomes, A.L. 2007. Contribuição para o conhecimento de Chytridiomycota da "Reserva Biológica de Paranapiacaba", Santo André, SP, Brasil. Biota Neotropica 3: 309-329.

Pires-Zottarelli, C.L.A. \& Rocha, M. 2007. Novas citações de Chytridiomycota e Oomycota para o Parque Estadual das Fontes do Ipiranga (PEFI), SP, Brasil. Acta Botanica Brasilica 21 : $125-136$

Pires-Zottarelli, C.L.A. \& Milanez, A.I. 1993. Fungos zoospóricos da Represa do Lobo ("Broa"). Novas citações para o Brasil. Revista Brasileira de Botânica 16: 205-220.

Pires-Zottarelli, C.L.A; Milanez, A.I.; Schoenlein-Crusius, I.H. \& Lohmann, L.G. 1996. Criptógamos do Parque Estadual das Fontes do Ipiranga, São Paulo, SP. Fungos, 6: Chytridiales. Hoehnea 23: $77-90$

Pires-Zottarelli, C.L.A.; Gomes, A.L. \& Nascimento, C.A. 2007. Entophlyctis luteolus in the Brazilian Atlantic Rainforest. Mycotaxon 99: 207-210.

Rocha, J.R.S. 2006. Filos Chytridiomycota e Oomycota. Pp. $75-$ 95. In: A.M. Giulietti (ed.). Diversidade e caracterização dos fungos do semi-árido. Recife, Associação Plantas do Nordeste.

Rocha, M. \& Pires-Zottarelli, C.L.A. 2002. Chytridiomycota e Oomycota da Represa de Guarapiranga, São Paulo, SP. Acta Botanica Brasilica 16: 287-309.

Rogers, A.L.; Milanez, A.I. \& Beneke, E.S. 1970. Additional aquatic fungi from São Paulo state. Rickia 5: 93-110.

Schoenlein-Crusius, I.H. \& Milanez, A.I. 1989. Sucessão fúngica em folhas de Ficus microcarpa L.f. submersas no lago frontal situado no Parque Estadual das Fontes do Ipiranga, São Paulo, SP. Revista de Microbiologia 20: 95-101.

Schoenlein-Crusius, I.H. \& Milanez, A.I. 1998. Fungos zoospóricos (Mastigomycotina) da mata Atlântica da Reserva Biológica do Alto da Serra de Paranapiacaba, município de Santo André, SP. Revista Brasileira de Botânica 2: 177-181.

Schoenlein-Crusius, I.H.; Pires-Zottarelli, C.L.A. \& Milanez, A.I. 1990. Sucessão fúngica em folhas de Quercus robur L. (carvalho) submersas em um lago situado no município de Itapecerica da Serra, SP. Revista de Microbiologia 21: 61-67.

Schoenlein-Crusius, I.H.; Pires-Zottarelli, C.L.A. \& Milanez, A.I. 1992. Aquatic fungi in leaves submerged in a stream in the Atlantic rainforest. Revista de Microbiologia 23: 167-171.

Schoenlein-Crusius, I.H.; Milanez, A.I.; Trufem, S.B.; Pires-Zottarelli, C.L.A; Grandi, R.P.; Santos, M.L. \& Giustra, K.C. 2006. Microscopic fungi of the Atlantic Rainforest in Cubatão, São Paulo, Brazil. Brazilian Journal of Microbiology 37: 244-252.

Secretaria do Meio Ambiente. 2003. Roteiro de Visitação do Parque Estadual da Serra da Cantareira, São Paulo, SP.

Seymour, R.L. 1971. Studies on mycoparasitic chytrids. I. The genus Septosperma. Mycologia 63: 83-93.

Sparrow Jr., F.K. 1936. Evidence for the possible occurrence of sexuality in Diplophlyctis. Mycologia 28: 321-323.

Sparrow Jr., F.K. 1957. A further contribution to the Phycomycete flora of Great Britain. Transactions of Britsh Mycological Society 40: 523-535.

Sparrow Jr., F.K. 1960. Aquatic Phycomycetes. $2^{\text {nd }}$ ed. Ann Arbor, University of Michigan Press.

Sparrow Jr., F.K. \& Lange, L. 1976. Some bog chytrids. Canadian Journal of Botany 55: 1879-1890.

Whiffen, A.J. 1942. Two new chytrid genera. Mycologia 34: 543-557.

Willoughby, L.G. 1965. A study of Chytridiales from Victorian and other Australian Soils. Archive für Mikrobiology 52: 101-131. 